\title{
Managing the development of digital educational games
}

\author{
Paula Hodgson \\ Faculty of Education \\ University of Hong Kong \\ etpaula@hku.hk
}

\author{
Donald Man \\ Showcase R\&D \\ Hong Kong \\ etdonald@gmail.com
}

\author{
Josa Leung \\ Showcase R\&D \\ Hong Kong \\ josa.design@gmail.com
}

\begin{abstract}
Based on the practical experience of developing webbased educational games in a joint universities project in Hong Kong, the authors discuss a 'seven-stage rapid game development model' with a 'dynamic fine tuning' of team composition. Reflection on lessons learned from the practical experience is described.
\end{abstract}

\section{Keywords-educational games; rapid game development model}

\section{INTRODUCTION}

The use of educational technologies for teaching in universities has been advocated for a decade in Hong Kong [1], with universities receiving funding from the University Grants Committee (UGC) to explore the extended learning opportunities offered by the web environment. University facilities have been upgraded, with the wide availability of on-campus wireless access to the Internet, resulting in more academics making use of online resources in their teaching. Academics are also becoming more aware of their students' wider experience of technology in schools. To keep pace with growing expectations for learning and teaching with modern learning technologies, some academics have taken the opportunity to apply for funding to modify the learning landscape in order to keep engaging and motivating their students.

Using digital games for learning is debatable, because games are commonly perceived as a tool for having fun. However, as players spend so much time in playing, educators may consider using the motivation to play and build lifelong learning skills. In fact, there has been a growing trend towards using educational games and simulations as one component of the effort to help students to master the challenges inherent in learning abstract concepts and to reflect on their learning experiences through these interactions [2]. More importantly, well-designed learning games allow active processing of information, and they stimulate learning curiosity [3]. When learners are required to explore and solve problems as they go through the tasks in a game, they start to build the skills needed to analyse a problem and to reflect on how they arrived at a solution [4][5]. By engaging students in an authentic but virtual learning environment, they can both learn content and acquire essential competences to face novelty through fun while being challenged [6][7].

This paper reports on the technical processes of a HK\$3.5 million joint universities project funded by the UGC between 2002 and 2004. The three universities involved were the Hong Kong Polytechnic University, the City University of Hong Kong and the Chinese University of
Hong Kong. The majority of deliverables were evaluated after the implementation. More details of the project can be found on the project website: http://e3learning.edc.polyu.edu.hk/ [8]. The project, e3Learning, adopted a 'multi-expertise' team 'processbased' support model in which the technical development team consisted of members with talents in web design and web programming and knowledge of current technological developments [8][9]. To ensure quality, the technical development team adopted the conventional instructional design model: (1) analysis, (2) design, (3) development, (4) implementation and (5) evaluation (ADDIE) [10]. There were clear lines of communication between academics, project manager, evaluation officer and technical development team.

\section{Managing Multiple Sub-PRojects With SEVEN STAGES OF RAPID GAME DEVELOPMENT}

To produce a pedagogical learning environment, production team members needed to develop a systemic process that allows maximum output. Building on experience from the past and coping with the intensive demand on the technical team for game development, the team adopted a new strategy for both the production process and team composition, especially for game development. First, the team classified the game deliverables into three categories, namely basic, moderate and complex. The classification was based on features, scale and complexity described in the requirements and specifications of subproject proposals. A sub-group consisted of three teams of specialists: content, design and graphics, and programming. The e3Learning team established a model to manage multiple sub-projects simultaneously and facilitate and maximize team efforts. This seven-stage model is a combination of the 'waterfall model' of traditional systems engineering and project management skills from PMBOK [11]. The team modified the model for game development to include design and multimedia production and worked on a 'seven-stage rapid game development model' with a 'dynamic fine tuning' of team composition.

However, building on experience from the past and coping with the intensive demand on the technical team for game development, the team adopted a new strategy for both the production process and team composition, especially for game development. First, the team classified the game deliverables into three categories, namely basic, moderate and complex. The classification was based on features, scale and complexity described in the requirements and specifications of sub-project proposals (see Table 1). 


\begin{tabular}{|c|c|}
\hline \multicolumn{2}{|r|}{ Moderate scale } \\
\hline $\begin{array}{l}\text { Coverage of } \\
\text { knowledge }\end{array}$ & $\begin{array}{l}\text { - Covering simple concepts (e.g. } \\
\text { elaboration of a formula) } \\
\text { - } \quad \text { Covering few topics of a subject }\end{array}$ \\
\hline Storyline & $\begin{array}{ll}\text { - } & \text { Delivering in a linear flow of story } \\
\text { - } & \text { pimited by fixed number of } \\
\text { parameters }\end{array}$ \\
\hline $\begin{array}{l}\text { Presentation } \\
\text { style/mode of } \\
\text { interaction }\end{array}$ & $\begin{array}{ll}\text { - } & \text { Story telling } \\
\text { - } & \text { Learners having some but limited } \\
\text { interactions with the content }\end{array}$ \\
\hline \multicolumn{2}{|l|}{ Complex scale } \\
\hline $\begin{array}{l}\text { Coverage of } \\
\text { Knowledge }\end{array}$ & $\begin{array}{ll}\text { - } & \text { Covering different subjects } \\
\text { - } & \text { Building competence or skill sets }\end{array}$ \\
\hline Storyline & $\begin{array}{l}\text { - Variable, dynamics and non-linear } \\
\text { flow of storyline of the game } \\
\text { - A variety of options that lead to } \\
\text { different outcomes of scenarios and } \\
\text { cases } \\
\text { - Integrative and collaborative } \\
\text { approaches }\end{array}$ \\
\hline $\begin{array}{l}\text { Presentation } \\
\text { style/mode of } \\
\text { interaction }\end{array}$ & $\begin{array}{l}\text { - Learners having multiple attempts } \\
\text { with variety of actions } \\
\text { - Comprehensive, with a complete } \\
\text { set of rules of the game, levelling } \\
\text { with bonus/penalty } \\
\text { - Personal portfolio: log and } \\
\text { performance achieved }\end{array}$ \\
\hline
\end{tabular}

Table 1: Classification of game deliverables

\section{Stage 1: Understanding content}

Content was first provided by a subject teacher. The technical officer and content team leader had initial meetings with the subject teacher to understand the expectations of the teacher and to clarify subject-specific concepts. The creative team leader also participated in the meetings. A working document was created that could be passed to the creative team to explore educational gamebased activities.

\section{Stage 2: Forming a learning game framework}

Based on the discussion by the content team conducted during stage 1, the creative team then brainstormed types of learning game or interactive task, which were in the form of a storyline for students to master the concepts. However, when a situational game such as SimCity, which has many variables and different outcomes, or a scenario-based activity such as Second Life was considered, creating the required learning environment was very time-consuming. The team had to match appropriate educational game activities with the intended learning outcomes and also to balance the cost and time required for development. A tentative internal storyboard document was created in stage 2 that included an outline of the storyline and types of educational game built in that matched the intended learning outcomes.

\section{Stage 3: Bundling learning game framework}

A meeting was held to discuss and review the tentative internal storyboard document to see whether it required modification. They would also discuss deliverable style, including storyline, nature (whether it was for social interactions, problem solving or inquiry-based) and types of educational game activity (whether closed-ended, sequential or situational/scenario-based), types of interaction that learners have (whether interacting with the computer, or asynchronously or synchronously with other participants). Afterwards, the creative team could include information on visual forms, such as hand-drawn sketches, photos, videos, two- or three-dimensional learning objects and FX effects with CG animation in the tentative internal storyboard document. The document was made comprehensive by the inclusion of input from the programming team on its initial technical analysis and proposed technological feasibility studies.

\section{Stage 4: Consolidating learning game framework}

The technical officer and the team leaders needed to get feedback from the subject teacher on the full set of documentation generated from stage 3 . The technical officer needed to negotiate with the subject lecturer where necessary. Once agreement had been reached, a feasible and acceptable work plan was set up in the next stage. A full production plan was drafted that included resource allocation and an estimate of the timeframe for production.

\section{Stage 5: Formulating production plan}

Based on the agreements generated in stage 4, the technical officer drafted a production plan that included work breakdown and structure for tasks for the teams, the timeframe for modular production, allocation of staff resources and acquisition of essential facilities. The members of each team were given a clear set of actions with a timeline for completion.

\section{Stage 6: Executing production plan}

At this stage, the creative and programming teams were working side by side. The content team could assist in reviewing the content and piloting the educational games to assess whether there were any bugs in the programming. Internal communication between team members was essential to minimize unanticipated events. However, meetings with the teams to collect internal feedback were also scheduled for when some key milestones were met. It was paramount to have good communication with the subject teacher, because the key to the rapid development approach is ensuring that the prototype is endorsed early by the subject lecturer. This could minimize costs by reducing time for rectification in the overall production process. As the production evolved, technical documentation was produced that included conversion of the design storyboard 
to the relevant systems architecture and coding documents, e.g. Excel file-naming convention for objects showing in different scenes. In addition, the coding system used in programming was filed to allow orderly control of versions. This can be used for monitoring and debugging, and as a reference for future maintenance.

\section{Stage 7: Fine-tuning learning game}

Educational games were live for testing, although the scale of testing depended on the anticipated volume of use. It was expected that more people would participate in the stress test if the volume of use was to be high. Former students who had studied the subject in the past could be invited to participate in the user acceptance test. Alternatively, students from the coming year could be invited to be the control group in the test. Lastly, fine-tuning on performance and appearance could be carried out according to the original design.

Overall, stages 1 to 5 aimed to formulate an agreed plan for an educational game framework, while stages 6 to 7 were to execute the production plan. Teams were not required to expend equal intensity of effort in each stage. As discussed earlier, the technical development team managed more than ten sub-projects, with over half having an educational game component. 'Dynamic fine-tuning" of team composition was activated once work had entered stage 1 of the 'seven-stage rapid game development model'. Team formation changed as work progressed to the next stage, and that depended on students' experience and their expertise in the team. For instance, a complex sub-project could include ten students in the content team and six students in the creative team. However, one or two leading members also participated in meetings in stage 1 . In stage 3 , three to four students with mixed abilities from the content team were involved in sharing students' experience and contributed to the discussion on delivery style, and the nature and type of educational games.

On the other hand, a moderate scale of sub-project might require fewer staffing resources and a shorter time to complete the tasks assigned. As the team members completed their roles in each stage, they could start working on another sub-project that could have a different team composition. This mechanism was extremely useful when limitations were availability of resources, especially personnel, and when project tasks overlapped in a given period.

\section{CONCLUSION}

Team development of educational games is always a challenge, but the seven stages of the life cycle of rapid game development frames the process of good planning from the beginning, with its emphasis on close communication with stakeholders and maximizing the creative talents for content, design and graphics and the skills of programming staff from the technical team to produce educational games for learning. The game production cycle in this instance was reduced from each game taking four months to five games being completed in six months. It requires efficient management systems and commitment to high-quality production with deep collaboration between stakeholders to achieve this.

\section{REFERENCES}

[1] N.J. French, "Encouraging quality teaching in higher education" [electronic version], Hong Kong, 1999, from http://ugc.edu.hk/eng/ugc/publication/speech/1999/njf_tt2_e.h tm. Accessed on 21 September 2009.

[2] S. de Freitas and M. Oliver, "How can exploratory learning with games and simulations within the curriculum be most effectively evaluated?" Computers \& Education, 2006, 46(3), 249-64.

[3] P.R. Ogershok and S. Cottrell, "The pediatric board game", Medical Teacher, 2004, 26(6), 514-17.

[4] Y.-J. An and C.J. Bonk, "Designing digital game-based learning environments", TechTrends: Linking Research and Practice to Improve Learning, 2009, 53(3), 43-8.

[5] A. Adcock, "Making digital game-based learning work: an instructional designer's perspective", Library Media Connection, 2008, 26(5), 56-7.

[6] W. Westera, R.J. Nadolski, H.G.K. Hummel and I.G.J.H. Wopereis, "Serious games for higher education: a framework for reducing design complexity", Journal of Computer Assisted Learning, 2008, 24(5), 420-32.

[7] Galarneau, L., \& Zibit, M. (2007). Online games for 21st century skills. In D. Gibson, C. Aldrich \& M. Prensky (eds), Games and Simulations in Online Learning: Research and Development Frameworks (pp. 59-88). Hershey, Pa., Information Science Publishers.

[8] P. Hodgson, P. Lam and Y.-H.E. Wong, "Dovetailing pedagogical and technical support with evaluation", International Journal on E-Learning, AACE, 2007, 6(3), 36378.

[9] P. Hodgson and P. Lam, "Quality management of a jointuniversity e-learning project: e3Learning. Global Education, July 2004: http://www.globaled.com/articles/PaulaHodgeson2004.pdf,

[10] W. Dick and L. Carey, The Systematic Design of Instruction, 4th edn. Harper Collins College Publishers, New York, 1996.

[11] PMI, A Guide to the Project Management Body of Knowledge (PMBOK Guide) 3rd edn, Project Management Institute, Newtown Square, Pa., 2004. 